http://dx.doi.org/10.32929/2446-8355.2019v28n2p123-137

\title{
DOSES E ÉPOCAS DE APLICAÇÃO DE BORO NA QUALIDADE DE SEMENTES DE SOJA
}

\author{
Mariana Pina da Silva Berti ${ }^{1 *}$, Marco Eustáquio de Sá $^{2}$, Cleiton Gredson Sabin Benett ${ }^{3}$, \\ Ednaldo Cândido Rocha ${ }^{4}$, Christian Luis Ferreira Berti ${ }^{5}$
}

\author{
${ }^{1}$ Docente, Dra em Agronomia, Nutrição de Plantas, Universidade Estadual de Goiás, Ipameri-GO. *E-mail do \\ autor correspondente: mariana.berti@ueg.br. \\ ${ }^{2}$ Professor Titular, Dr. em Agronomia, Tecnologia de Sementes, Unesp, Ilha Solteira - SP. \\ ${ }^{3}$ Docente, Dr. em Agronomia, Fitotecnia, Universidade Estadual de Goiás, Ipameri-GO. \\ ${ }^{4}$ Docente, Dr. em Ciência Florestal, Ecologia e Conservação de Recursos Naturais, Universidade Estadual de \\ Goiás, Ipameri-GO. \\ ${ }^{5}$ Biologo, Dr. em Agronomia.
}

Recebido: 12/11/2018; Aceito: 31/05/2019

\begin{abstract}
RESUMO: O presente trabalho teve por objetivo avaliar o efeito de doses de boro (B) em cinco épocas (estádios fenológicos) na qualidade fisiológica de sementes da variedade de soja M 7110 IPRO. O projeto foi realizado no Laboratório da Universidade Estadual de Goiás UEG, Campus Ipameri, localizado no município de Ipameri-GO. O delineamento experimental utilizado foi inteiramente casualizado em esquema fatorial $5 \times 6$ com quatro repetições, sendo seis doses de $\mathrm{B}\left(0,1,2,3,4\right.$ e $\left.5 \mathrm{~kg} \mathrm{ha}^{-1}\right)$ aplicadas via solo, utilizando como fonte o ácido bórico (17\%), em cinco épocas de aplicação: semeadura, estádio V3 ( segundo trifólio aberto), V6 (sétima folha trifoliolada completamente aberta), V9 (décima folha trifoliolada completamente aberta) e R1 (início do florescimento) As análises laboratoriais foram realizadas no Laboratório de Sementes da Universidade Estadual de Goiás - UEG, Campus Ipameri, sendo avaliados os seguintes testes de vigor: germinação padrão, primeira contagem de germinação, condutividade elétrica, emergência de plântulas em campo, comprimento de plântula e massa da matéria seca de plântula. A aplicação via solo de B é mais adequada na semeadura da soja proporcionado sementes com maior vigor. A qualidade fisiológica das sementes foi influenciada pela aplicação de 2,5 e 3,0 $\mathrm{kg} \mathrm{ha}^{-1}$ de boro.
\end{abstract}

Palavras-chave: Glycine max. Adubação. Micronutriente. Fenologia.

\section{DOSES AND TIMES OF APPLICATION OF BORO IN THE QUALITY OF SOYBEAN SEEDS}

\begin{abstract}
The objective of this work was to evaluate the effect of Boron (B) doses in five seasons (phenological stages) on the physiological quality of seeds of the M 7110 IPRO soybean variety. The project was carried out at the Laboratory of the State University of Goiás - UEG, Campus Ipameri, located in the municipality of Ipameri-GO. The experimental design was completely randomized in a $5 \times 6$ factorial scheme with four replicates. Six B doses $(0,1,2,3,4$ and $5 \mathrm{~kg}$ ha-1) were applied via soil using boric acid ( 17), in five seasons of application: sowing, V3 stage (second open trefoil), V6 (seventh fully open trifoliolate
\end{abstract}


leaf), V9 (tenth trifoliolate fully open) and R1 (beginning of flowering) Laboratory analyzes were performed in Laboratory of seeds of the State University of Goiás - UEG, Ipameri Campus. The following vigor tests were evaluated: standard germination, first germination count, electric conductivity, seedling emergence in the field, seedling length and mass of dry matter of seedlings. The soil application of B is more adequate in the sowing of soybean provided seeds with greater vigor. The physiological quality of the seeds was influenced by the application of 2.5 and $3.0 \mathrm{~kg} \mathrm{ha}^{-1}$ of boron.

Key words: Glycine max. Fertilizing. Micronutrient. Phenology.

\section{INTRODUÇÃO}

O Brasil encontra-se como o segundo maior produtor de soja, cuja expansão técnica e científica apresentou avanços consideráveis. A cultura da soja tem importância na economia nacional, pois envolve diversos agentes e organizações em vários setores econômicos, desempenhando papel fundamental para o Produto Interno Bruto (HIRAKURI; LAZZAROTTO, 2011).

Os avanços científicos da última década na utilização de produtos químicos (inseticidas, herbicidas e fertilizantes), bem como o uso de cultivares mais produtivos, permitiram aumento significativo na produção e produtividade da soja. Dentre esses avanços, destaque especial pode ser dado à utilização de fertilizantes minerais e sementes de alta qualidade (SUZANA et al, 2012; PESKE et al., 2012).

O boro (B) é indispensável à germinação do grão de pólen, ao crescimento do tubo polínico e, consequentemente, fecundação da flor (MARSCHENER, 1995), além de estar relacionado ao metabolismo de carboidratos, transporte de açúcares, síntese de RNA, DNA e fito-hormônios, formação das paredes celulares, divisão celular e desenvolvimento de tecidos (DECHEN, 1988; BORKET, 1989).

Malavolta (2006) enfatizou que o B aumenta o pegamento de flores e a granação em culturas, e propicia menor esterilidade masculina e chochamento de grãos. A exigência nutricional das plantas cultivadas torna-se, em geral, mais intensa com o início da fase reprodutiva, pois as lavouras encontram-se em pleno desenvolvimento vegetativo, somado à forte demanda por nutrientes para a formação das estruturas reprodutivas (CARVALHO; NAKAGAWA, 2000)

O B tem sido objeto de muitos estudos em virtude das suas funções no metabolismo vegetal, sendo importante para obtenção de maiores produtividades e qualidade de sementes (FÁTIMA, 2013). Segundo Furlani et al. (2001), a soja é uma das culturas anuais mais exigentes em $\mathrm{B}$, sendo comum a deficiência nessa cultura. De maneira geral, a exigência nutricional das culturas é maior com o início da fase reprodutiva e essa alta exigência é devido ao fato de os nutrientes serem essenciais à formação e ao desenvolvimento de novos órgãos de reserva (CARVALHO; NAKAGAWA, 2000).

Resultados de pesquisa acerca da influência de B na qualidade fisiológica de sementes são contraditórios, como de Ohse et al. (2001) e Ribeiro et al. (1994), em sementes de arroz e 
milho, respectivamente. Segundo esses autores supracitados, a aplicação de B proporcionou redução na germinação e vigor. Todavia, Almeida et al. (2015), Leite et al. (2011) e Lima et al. (2013) verificaram em sementes de Capim Mombaça, arroz, feijão comum e mamona, respectivamente, que a qualidade dessas não foi influenciada pela aplicação foliar de B.

Bevilaqua et al. (2002), avaliando a qualidade fisiológica de sementes de soja constataram que a aplicação foliar com cálcio $(\mathrm{Ca})$ e $\mathrm{B}$ não melhorou a qualidade das sementes, independentemente da época de aplicação. Kappes et al. (2008) também verificaram que a qualidade fisiológica das sementes de soja não foi influenciada pela aplicação foliar de B, onde neste experimento as sementes não atingiram qualidade necessária à comercialização (acima de $80 \%$ de germinação).

Para um bom crescimento e desenvolvimento da cultura, é necessário um bom manejo nutricional, com macro e micronutrientes. Os últimos, apesar de serem exigidos em menores quantidades, são igualmente importantes para as plantas. Entre os micronutrientes, o boro se destaca por desempenhar na planta funções diretamente ligadas à produção. Considerando que trabalhos realizados com respostas de boro na cultura da soja são poucos e com resultados divergentes, torna-se necessário a realização de novos estudos que possibilitem a utilização deste micronutriente de forma coerente nesta cultura

Portanto, objetivou-se com este trabalho avaliar o efeito de doses e épocas de aplicação de B na qualidade fisiológica de sementes, na cultura da soja implantada sob sistema de plantio direto.

\section{MATERIAL E MÉTODOS}

O experimento foi implantado em Novembro na Universidade Estadual de Goiás UEG, Campus Ipameri, localizado no município de Ipameri-GO com $17^{\circ} 07^{\prime}$ de latitude sul e 48 09' 49' de longitude oeste e altitude de 800 m. Conforme a classificação de Koppen, o clima da região é tropical (Aw) com estação seca de Inverno e chuvas no verão.

O solo da área experimental foi classificado como Latossolo Vermelho-Amarelo distrófico textura argilosa (SANTOS et al., 2013). Os atributos químicos do solo foram determinados antes da instalação do experimento, segundo metodologia proposta por Ribeiro et al. (1999) com os seguintes atributos químicos na camada 0,0-0,20 m: 9,3 mg dm${ }^{-3}$ de $\mathrm{P}$ (Melich); 17,1 $\mathrm{g} \mathrm{dm}^{-3}$ de M.O.; 6,20 de pH $\left(\mathrm{CaCl}_{2}\right)$; $\mathrm{K}$ 0,26; Ca 2,40; $\mathrm{Mg} \mathrm{0,90;} \mathrm{e} \mathrm{H}+\mathrm{Al}=1,70$ mmolc $\mathrm{dm}^{-3}$, respectivamente, $67,7 \%$ de saturação por bases e o teor de B foi de $0,20 \mathrm{mg} \mathrm{dm}^{-}$ ${ }^{3}$, sendo considerado baixo no solo.

O delineamento experimental utilizado foi o inteiramente casualizado em esquema fatorial 5 x 6 com quatro repetições. Sendo as épocas de aplicação de B: semeadura; estádio V3 (segundo trifólio aberto); V6 (sétima folha trifoliolada completamente aberta); V9 (décima folha trifoliolada completamente aberta) e R1 (início do florescimento). A aplicação de B na semeadura foi realizada no sulco de plantio, e o restante em cobertura, ao lado das plantas de soja, de acordo com as épocas de desenvolvimento da cultura, conforme escala fenológica de Ritchie et al. (1977). Sendo as doses de B (0, 1, 2, 3, 4 e $\left.5 \mathrm{~kg} \mathrm{ha}^{-1}\right)$, aplicada via solo, utilizando o fertilizante ácido bórico (17\%). 
Cada parcela foi constituída de seis linhas de cinco metros de comprimento, com espaçamento de $0,45 \mathrm{~m}$, perfazendo uma área de $13,5 \mathrm{~m}^{2}$. A área considerada útil foi constituída pelas três linhas centrais, desprezando-se 1,0 m em ambas as extremidades de cada linha.

Para a semeadura da soja utilizou-se sementes da cultivar M 7110IPRO na qual foram inoculadas com Estirpes Bradyrhizobium japonicum. SEMIA 5079 e 5080, ciclo precoce, com maturação entre 105 e 108 dias para a região de plantio e com ampla adaptação geográfica. A cultura foi implantada sob sistema plantio direto (7 anos), com palhada de Urochloa decumbens.

A adubação de plantio foi realizada de acordo com a análise do solo e segundo recomendação de Ribeiro et al. (1999) no momento do plantio com $200 \mathrm{~kg} \mathrm{ha}^{-1}$ de 05-20-15.

A colheita foi realizada manualmente em fevereiro com os grãos com 13\% umidade quando a cultivar atingiu de 80 a $90 \%$ de desfolha. Nessa ocasião as plantas da área útil foram acondicionadas em sacos de juta identificados e encaminhadas ao Laboratório para realizar as seguintes avaliações:

Teste de Germinação: conduzido com quatro subamostras de 50 sementes por tratamento, distribuídas em rolos de papel germitest umedecidos na proporção de 2,5 vezes sua massa seca, utilizando água deionizada. Posteriormente, os rolos de papel foram inseridos no germinador regulado à temperatura constante de $25 \pm 2^{\circ} \mathrm{C}$. Os testes foram interpretados aos cinco e oito dias após a semeadura, computando-se a porcentagem de plântula normais, de acordo com os critérios estabelecidos nas Regras para Análise de Sementes (BRASIL, 2009).

Primeira contagem: realizada em conjunto com o Teste de Geminação, determinando-se a percentagem de plântulas normais no quinto dia após a semeadura.

Condutividade elétrica: conduzido conforme o método descrito por Marcos Filho (2005), com quatro subamostras de 50 sementes por tratamento, cujas massas foram previamente determinadas. Após a determinação da massa de cada amostra, as sementes foram colocadas em copos plásticos contendo $75 \mathrm{~mL}$ de água deionizada, mantidas em germinador a temperatura de $25 \pm 2^{\circ} \mathrm{C}$ ), com fotoperíodo de 12 horas, durante 24 horas. Decorrido esse período, a condutividade da solução foi determinada com o uso do Condutivímetro Gehaka modelo CG1400. Foi determinada a condutividade da água e o valor obtido foi subtraído do valor da condutividade da solução, e divididos pela massa da amostra (g), sendo os resultados expressos em $\mu \mathrm{S} \mathrm{cm}^{-1} \mathrm{~g}^{-1}$ de sementes.

Comprimento de plântulas: cinco amostras de 20 sementes de cada tratamento foram distribuídas em rolos de papel germitest umedecidos com água deionizada na proporção de 2,5 vezes a massa seca, e inseridos e mantidos em germinador a $25^{\circ} \mathrm{C}$, durante cinco dias (NAKAGAWA, 1999). Sobre o papel germitest umedecido foi traçada uma linha no terço superior, na direção longitudinal, onde as sementes foram colocadas direcionando-se a micrópila para baixo. O comprimento das plântulas consideradas normais (BRASIL, 2009) foi determinado ao final do quinto dia, com o auxílio de régua milimetrada. 
Massa da matéria seca de plântula: As plântulas submetidas à avaliação do comprimento foram encaminhadas à estufa de circulação forçada de ar $\left(65^{\circ} \mathrm{C}\right)$ até a obtenção de massa constante. Posteriormente, utilizou-se uma balança de precisão de $0,001 \mathrm{~g}$, a fim de determinação da massa da matéria seca das plântulas.

Emergência de plântulas em campo: realizada a partir da semeadura de quatro subamostras de 50 sementes por tratamento em solo da área experimental umedecido, conduzido em condições ambientais, distribuídas em sulcos e cobertas com uma fina camada de solo. As plântulas emergidas foram contadas diariamente entre o início da emergência ( $5^{\circ}$ dia) até o momento de estabilização numérica das contagens ( $10^{\circ}$ dia após a semeadura), determinando-se a porcentagem de emergência de plântulas normais (NAKAGAWA, 1994).

Os dados foram submetidos à análise de variância (teste F) e as médias comparadas pelo teste Tukey a 5\% de probabilidade. Para as doses de B foi utilizada a análise de regressão. As análises estatísticas foram processadas através do programa de análise estatística Sisvar (FERREIRA, 2011).

Utilizando os dados obtidos em cada estádio fenológico das plantas, foi realizada a análise de correlação linear de Pearson, cujos resultados foram representados em forma gráfica. Essas análises estatísticas foram conduzidas utilizando o software R versão 3.5.1 (R CORE TEAM, 2018), utilizando o pacote corrplot (WEI; SIMKO, 2017).

\section{RESULTADOS E DISCUSSÃO}

As doses de B, bem como a época de aplicação influenciaram o teste padrão de germinação e a primeira contagem da germinação (Tabela 1). De modo geral, houve maior percentagem de plântulas normais nessas respectivas avaliações quando se realizou a aplicação de B na semeadura. Portanto, é importante a adubação boratada, sobretudo na semeadura, uma vez que esta aplicação influenciou positivamente o vigor das sementes, proporcionando maior percentagem de plântulas normais.

As doses de B também influenciaram a percentagem de plântulas normais na primeira contagem. Houve ajuste à função quadrática, sendo $82 \%$ a máxima percentagem de plântulas normais obtida com a aplicação de $2,5 \mathrm{~kg} \mathrm{ha}^{-1}$ de B.

Com relação aos valores de porcentagem de plântulas normais no teste padrão de germinação verificou-se que, quando se realizou a aplicação de B no estádio R1, houve aumento do percentual de germinação das sementes de soja (Tabela 1).

Conforme Rosolem e Boaretto (1989), a época de aplicação exerce influência na produtividade de grãos e produção de sementes, pois a época de maior demanda de nutrientes pelas plantas de soja ocorre nos estádios R1 a R5.

A exigência nutricional das culturas, em geral, torna-se mais intensa com o início da fase reprodutiva. Essa maior exigência deve-se ao fato de os nutrientes serem essenciais à formação e ao desenvolvimento de novos órgãos de reserva (CARVALHO; NAKAGAWA, 2000). A quantidade de B requerida para a formação da semente geralmente é maior do que a necessária para o crescimento vegetativo (MARSCHNER, 1995). 
Tabela 1. Primeira contagem da germinação (PCG), teste padrão de germinação (GP) e condutividade elétrica (EA) das sementes da variedade de soja M-SOY 7110IPRO sob doses e épocas de aplicação de boro. UEG, Ipameri, 2017/2018. First germination (PCG), germination (GP) and electrical conductivity (EA) counts of the soybean seeds M-SOY $7110 I P R O$ under rates and times of boron application. UEG, Ipameri, 2017/2018.

\begin{tabular}{cccc}
\hline & PCG & GP & CE \\
\cline { 2 - 4 } Época de aplicação & \% de plântulas normais & $\mu \mathrm{S} \mathrm{cm}^{-1} \mathrm{~g}^{-1}$ \\
Semeadura & $85,3 \mathrm{a}$ & $89,2 \mathrm{a}$ & $177,3 \mathrm{c}$ \\
V3 & $74,0 \mathrm{~b}$ & $78,1 \mathrm{~b}$ & $192,1 \mathrm{~b}$ \\
V6 & $73,2 \mathrm{~b}$ & $77,2 \mathrm{~b}$ & $207,6 \mathrm{a}$ \\
V9 & $74,8 \mathrm{~b}$ & $79,3 \mathrm{~b}$ & $197,0 \mathrm{~b}$ \\
R1 & $77,6 \mathrm{~b}$ & $94,70 \mathrm{a}$ & $81,7 \mathrm{~d}$ \\
\hline Dose de boro $\left(\mathrm{kg} \mathrm{ha}^{-1}\right)$ & & & \\
0 & $70,7(1)$ & $77,0^{(2)}$ & 202,5 \\
1 & 80,5 & 83,4 & 171,8 \\
2 & 83,6 & 87,0 & 202,0 \\
3 & 75,2 & 80,0 & 188,2 \\
4 & 77,1 & 80,1 & 224,8 \\
5 & 73,9 & 78,2 & 171,7 \\
\hline & & Valores de F & \\
Época de aplicação (A) & $20,340^{* *}$ & $23,478^{* *}$ & $26,276^{* *}$ \\
Dose de boro (B) & $9,041^{* *}$ & $6,833^{* *}$ & $46,678 \mathrm{~ns}$ \\
A X B & $28,361 \mathrm{~ns}$ & $34,706 \mathrm{~ns}$ & $31,162 \mathrm{~ns}$ \\
CV (\%) & 8,04 & 6,92 & 6,21 \\
\hline
\end{tabular}

Médias seguidas por letras distintas minúsculas nas colunas diferem entre si pelo teste de tukey a $5 \%$ de probabilidade.ns: Valores não diferem segundo o teste $\mathrm{F}$ a $1 \%$ de probabilidade.** Médias significativas segundo o teste $\mathrm{F}$ a $1 \%$ de probabilidade. ${ }^{(1)} \mathrm{y}=72,89+6,17 \mathrm{x}-1,25 \mathrm{x}^{2} \mathrm{r}^{2}=0,54{ }^{(2)} \mathrm{y}=81,25+4,20 \mathrm{x}-0,88 \mathrm{x}^{2}$ $\left(\mathrm{r}^{2}=0,57\right)$. Means followed by lower case distinct letters in the columns differ from each other by the tukey test at $5 \%$ probability. ns: Values do not differ according to the $F$ test at $1 \%$ probability. ** Significant means according to the $F$ test at $1 \%$ probability. (1) $y=72.89+6.17 x-1.25 x^{2} r^{2}=0.54$ (2) $y=81.25+4.20 x-0.88 x^{2}$ $\left(r^{2}=0.57\right)$.

Para Faquin (1994), a exigência de B é normalmente maior para a produção de sementes e grãos, do que para o crescimento vegetativo das plantas, devido a sua participação no processo de fertilização.

De acordo com os padrões exigidos para produção e comercialização de sementes de soja (BRASIL, 2005), somente as aplicações de B na semeadura e no estádio R1 obtiveram valores considerados aceitáveis (> 80\%) em relação à percentagem de plântulas normais no teste padrão de germinação.

Em relação às doses de $\mathrm{B}$, os dados foram ajustados a uma função quadrática, na qual a percentagem máxima de plântulas normais no teste padrão de germinação foi de $82 \%$, obtida com a aplicação de $2,5 \mathrm{~kg} \mathrm{ha}^{-1}$ de B. 
Conforme descrito por Hanson (1991) e Teixeira et al. (2005), a disponibilidade de nutrientes influencia na formação do embrião e dos cotilédones, com efeito positivo sobre o aumento do vigor e da qualidade fisiológica das sementes. Resultados favoráveis foram verificados por Malavolta (2006) avaliando três estádios fenológicos (V6, V9 e R1) e cinco doses de boro $\left(0,1,2,3\right.$ e $\left.4 \mathrm{~kg} \mathrm{ha}^{-1}\right)$ na cultura da soja. Estes resultados se assemelham com os obtidos por Mondo et al. (2012) e Gazolla-Neto et al. (2015).

De encontro a esses resultados, Ambrosano et al. (1999), avaliando o efeito da adubação com micronutrientes ( $\mathrm{B}, \mathrm{Cu}, \mathrm{Fe}, \mathrm{Mn}$ e $\mathrm{Mo}$ ) na qualidade fisiológica de sementes de feijoeiro, constataram que os tratamentos não interferiram na percentagem de germinação e de plântulas anormais, sendo que estas não alteraram a qualidade das sementes determinada pelo teste de germinação. Bevilaqua et al. (2002), avaliando a qualidade fisiológica de sementes de soja com botões florais fechados, $80 \%$ das flores abertas, constataram que a aplicação foliar, com $\mathrm{Ca}$ e B, não melhorou a qualidade das sementes produzidas em nenhum dos estádios de aplicação. De acordo com Kappes (2008), a aplicação de doses de B via foliar em V5, V9 e R3, não proporcionou melhoria na qualidade de sementes de soja, determinado pelo teste de germinação, fato esse observado no trabalho em questão.

A época da aplicação de B influenciou a condutividade elétrica das sementes, sendo constatada menor condutividade elétrica quando se realizou a adubação boratada no estádio R1 (Tabela 1).

De acordo com Krzyzanowski et al. (1999), valores elevados da condutividade elétrica são ocasionados pela maior liberação de íons no meio, devido ao comprometimento da integridade das membranas, estando relacionado com a baixa qualidade das sementes, comprovando, possivelmente, que a aplicação de B no estádio R1 proporciona maior potencial de germinação das sementes.

Houve interação significativa entre época de aplicação e doses de B para o comprimento de plântulas, massa seca de plântulas e emergência de plântulas em campo (Tabela 2). Com o desdobramento das interações (épocas de aplicação $\mathrm{x}$ doses) verificou-se que as épocas apresentaram comportamentos distintos em relação ao comprimento de plântulas, massa seca de plântulas e emergência de plântulas em campo (Figuras 1, 2 e 3 respectivamente).

De acordo com a análise de regressão (Figura 1), o modelo linear foi o que melhor se ajustou aos dados de comprimento de plântulas no estádio V9, apresentando coeficiente de determinação de 74\%. Entretanto, no estádio R1 o modelo quadrático foi o que melhor se ajustou aos valores de comprimento de plântulas, com coeficiente de determinação de $71 \%$. Nesse estádio, as plântulas atingiram máximo comprimento $(9,4 \mathrm{~cm})$ com a aplicação de 2,3 $\mathrm{kg} \mathrm{ha}^{-1}$ de $\mathrm{B}$, sendo está muito próxima à dose que proporcionou maior percentagem de plântulas normais na primeira contagem e no teste de germinação. 
Tabela 2. Comprimento de plântulas (CP), Massa seca de plântulas (MS) e Emergência de plântulas em campo (EPC) das sementes da variedade de soja M-SOY 7110IPRO sob doses e épocas de aplicação de boro. UEG, Ipameri, 2017/2018. Length of seedlings (CP), seedling dry mass (DM) and emergence of field seedlings (EPC) of the seeds of soybean variety $M$ SOY 7110IPRO under rates and times of application of boron. UEG, Ipameri, 2017/2018.

\begin{tabular}{|c|c|c|c|}
\hline & $\mathrm{CP}(\mathrm{cm})$ & MS (g planta $\left.{ }^{-1}\right)$ & $\mathrm{EPC}(\%)$ \\
\hline \multicolumn{4}{|l|}{ Época de aplicação } \\
\hline Semeadura & 7,6 & 0,56 & 91,1 \\
\hline V3 & 4,1 & 0,45 & 81,7 \\
\hline V6 & 7,9 & 0,51 & 79,3 \\
\hline V9 & 9,7 & 0,77 & 83,2 \\
\hline $\mathrm{R} 1$ & 7,3 & 0,55 & 94,7 \\
\hline \multicolumn{4}{|l|}{ Dose de boro $\left(\mathrm{kg} \mathrm{ha}^{-1}\right)$} \\
\hline 0 & 5,2 & 0,54 & 82,6 \\
\hline 1 & 9,4 & 0,66 & 86,9 \\
\hline 2 & 6,9 & 0,54 & 91,9 \\
\hline 3 & 6,8 & 0,55 & 85,6 \\
\hline 4 & 8,3 & 0,54 & 85,8 \\
\hline 5 & 7,1 & 0,58 & 83,3 \\
\hline \multicolumn{4}{|c|}{ Valores de F } \\
\hline Época de aplicação (A) & $83,434 * *$ & $189,117 * *$ & $172,588 * *$ \\
\hline Dose de boro (B) & $34,951 * *$ & $23,184 * *$ & $36,746 * *$ \\
\hline A X B & $20,924 * *$ & $25,741 * *$ & $114,695^{* *}$ \\
\hline $\mathrm{CV}(\%)$ & 14,89 & 7,74 & 2,85 \\
\hline
\end{tabular}

** Valores de $\mathrm{F}$ significativos a $1 \%$ de probabilidade. ** Significant $F$ values at $1 \%$ probability.

O efeito positivo da adubação boratada sobre o crescimento de plântulas é explicado pelas funções deste nutriente nas plantas. O B é um ativador de enzimas que atuam em diversos processos metabólicos, tais como transporte de carboidratos, metabolismo das auxinas e formação de raízes por meio da divisão, alongamento celular e junção da parede celular e atividade das membranas celulares (MARSCHNER, 1995; LUND et al., 1996; ONO; RODRIGUES, 1996).

Em relação à massa seca de plântulas, o modelo linear foi o que melhor se ajustou à interação doses de B x época de aplicação (V9), com coeficiente de determinação de $58 \%$ (Figura 2). Contudo, nos estádios V3 e R1 houve ajuste ao modelo quadrático, com 51 e 71\% de coeficiente de determinação $\left(\mathrm{r}^{2}\right)$, respectivamente (Figura 2). A aplicação de $2,9 \mathrm{~kg} \mathrm{ha}^{-1} \mathrm{de}$ $\mathrm{B}$ no estádio V3 proporcionou a máxima massa seca de plântula $\left(0,39 \mathrm{~g}^{\mathrm{g}}\right.$ planta $\left.^{-1}\right)$, enquanto que a aplicação de $1,8 \mathrm{~kg} \mathrm{ha}^{-1}$ de B no estádio R1 resultou em maior massa seca de plântula $\left(0,58\right.$ g planta $\left.^{-1}\right)$. 


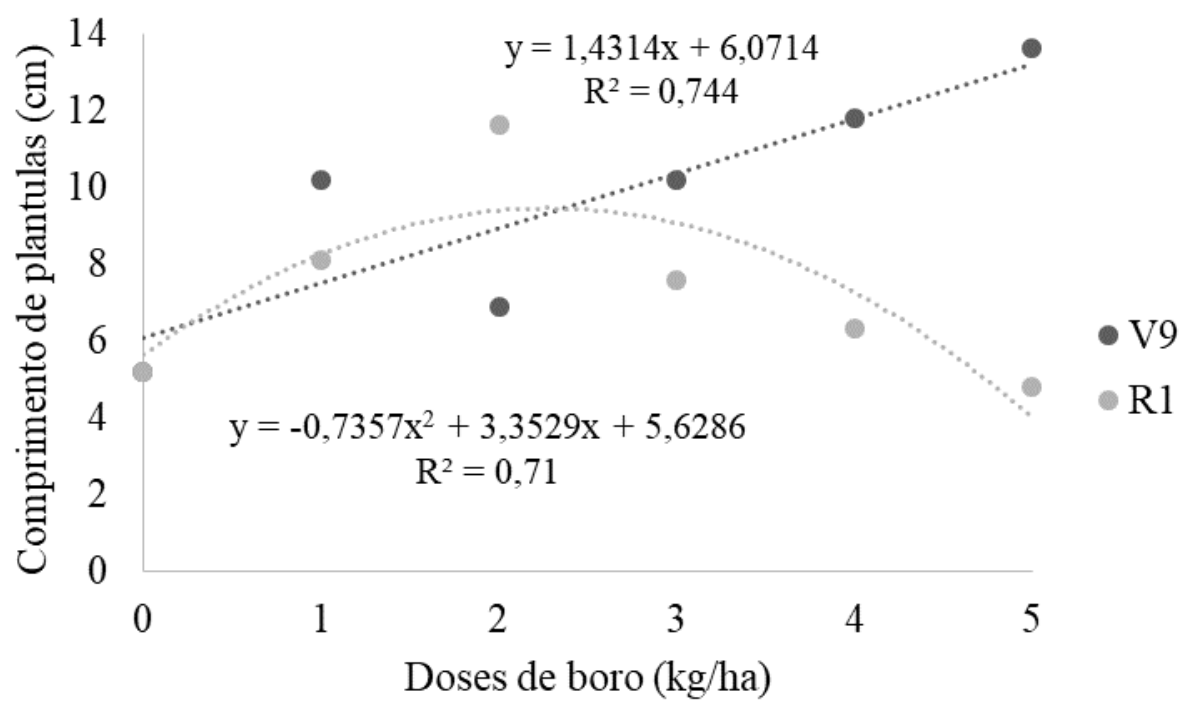

Figura 1. Comprimento de plântulas da variedade de soja M-SOY 7110IPRO em função da interação significativa entre épocas e doses de aplicação de boro. UEG, Ipameri, 2017/2018. Length of seedlings of the soybean variety M-SOY 7110IPRO as a function of the significant interaction between times and doses of boron application. UEG, Ipameri, 2017/2018.

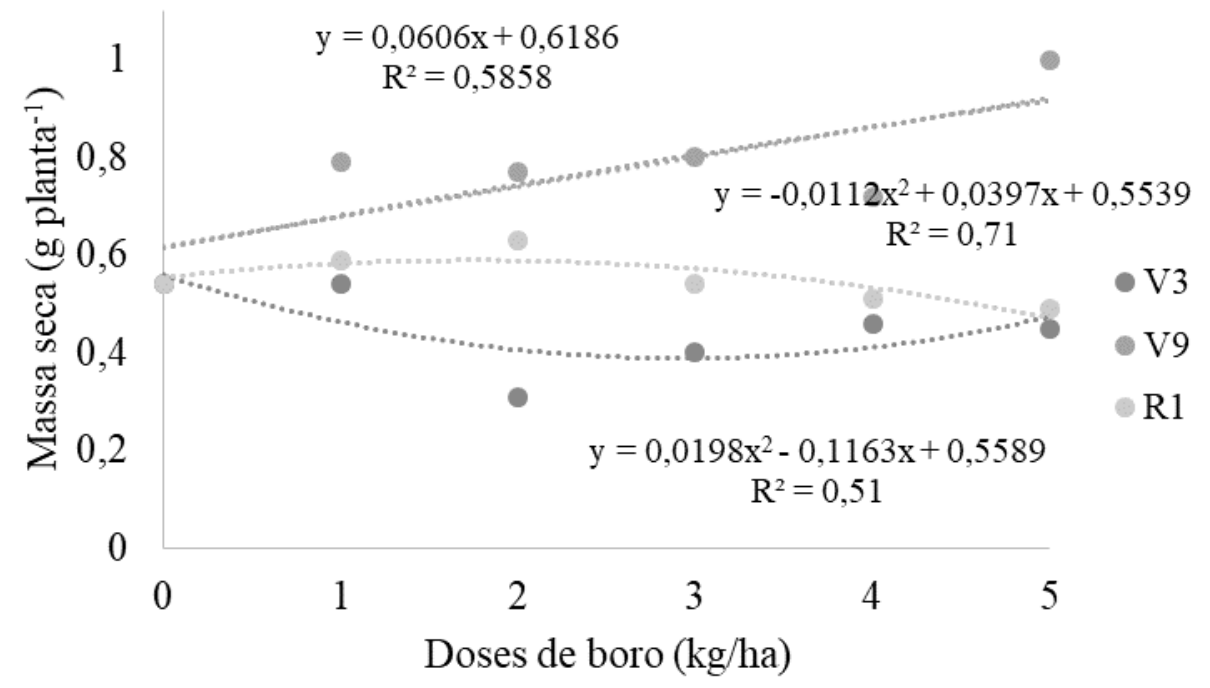

Figura 2. Massa seca de plântulas da variedade de soja M-SOY 7110IPRO em função da interação significativa entre épocas e doses de aplicação de boro. UEG, Ipameri,2017/2018. Dry mass of seedlings of soybean variety M-SOY 7110IPRO due to the significant interaction between times and doses of boron application. UEG, Ipameri, 2017/2018.

Este resultado demonstra a importância do B, sobretudo na translocação de açúcares para os órgãos propagativos. Entretanto, cabe destacar que o B é o nutriente que apresenta a menor faixa entre a zona de deficiência e toxidez, o que pode explicar o comportamento quadrático verificado no presente trabalho. Resultados semelhantes foram encontrados por Huang et al. (2000) em experimento com plântulas de girassol cultivadas em solução nutritiva, que verificaram correlação positiva entre o rendimento de massa seca e a concentração de B. 
Realizada a análise de regressão para a variável emergência de plântulas em campo, verificou-se que as aplicações das doses de B na semeadura e estádio V3 ajustou-se ao modelo quadrático, com coeficientes de determinação de 58 e $79 \%$, respectivamente. A aplicação de $3,5 \mathrm{~kg} \mathrm{ha}^{-1}$ de $\mathrm{B}$ na semeadura proporcionou a máxima emergência de plântulas à campo. A aplicação no estádio V3 apresentou a massa seca de plântula máxima com a aplicação de 2,3 kg B ha ${ }^{-1}$. Todavia Bevilaqua et al. (2002) constataram que a aplicação de B não influenciou a emergência de plântulas.

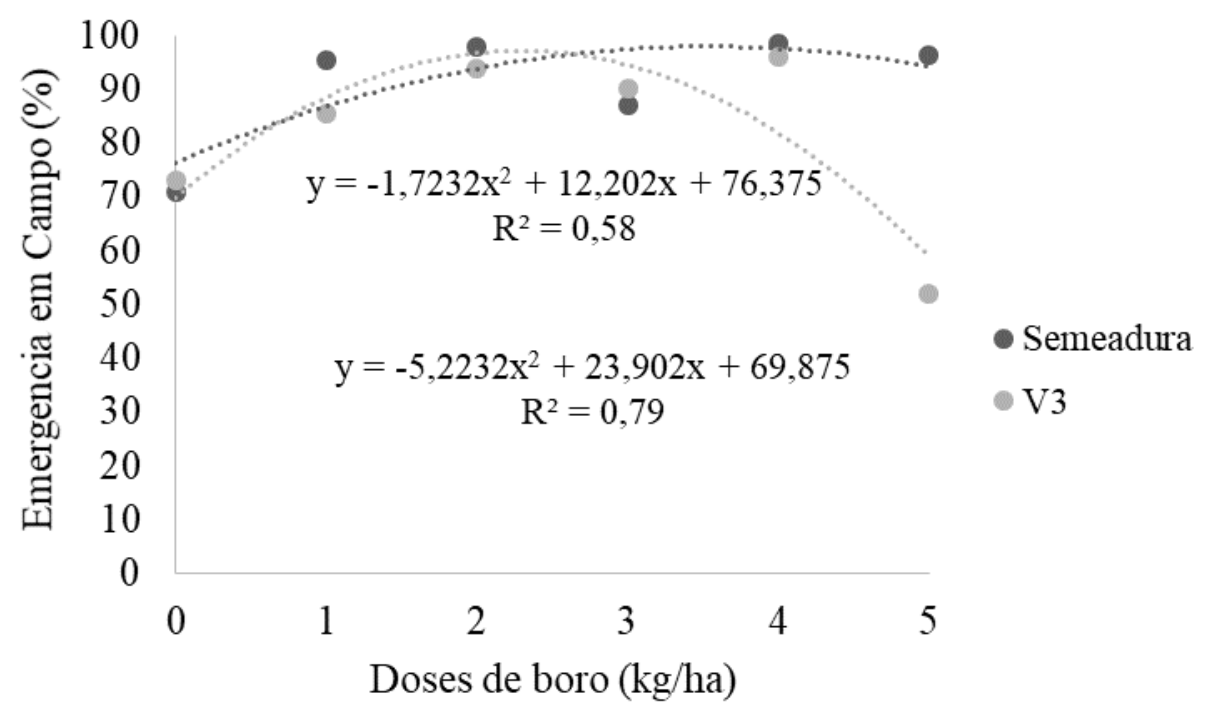

Figura 3. Emergência de plântulas em campo da variedade de soja M-SOY 7110IPRO em função da interação significativa entre épocas e doses de aplicação de boro. UEG, Ipameri, 2017/2018. Emergence of field seedlings of the soybean variety M-SOY 7110IPRO due to the significant interaction between times and doses of boron application. UEG, Ipameri, $2017 / 2018$.

O boro está estritamente relacionado com a qualidade fisiológica da semente por atuar diretamente no crescimento do tubo polínico durante o processo de fecundação (MARSCHNER, 1995; LEITE et al., 2011). A melhoria na qualidade fisiológica de sementes em função da adubação com boro foi verificada por outros autores (FARINELLI et al., 2006; SILVA et al., 2006).

$\mathrm{Na}$ Figura 4 constam os resultados da análise de correlação linear de Pearson das variáveis estudadas no presente estudo. Para o estádio fenológico V0, V3, V6 e V9 observouse correlação positiva significativa $(\mathrm{p}<0,05)$ entre as variáveis: primeira contagem de germinação (PCG) e germinação (GE); PCG e emergência de plântulas no campo (EPC); e GE e EPC (Figura 4). Segundo França-Neto, Krzyzanowski e Henning (2011), o uso de sementes vigorosas assegura o estabelecimento de uma população adequada de plantas, mesmo sob condições estressantes. Dantas et al. (2007) constataram que a primeira contagem de germinação é um método eficaz para a predição do vigor e diferenciação do nível de tolerância das sementes ao estresse. Assim, lotes de sementes com maiores valores de germinação na primeira contagem e maior velocidade são considerados mais vigorosos. 


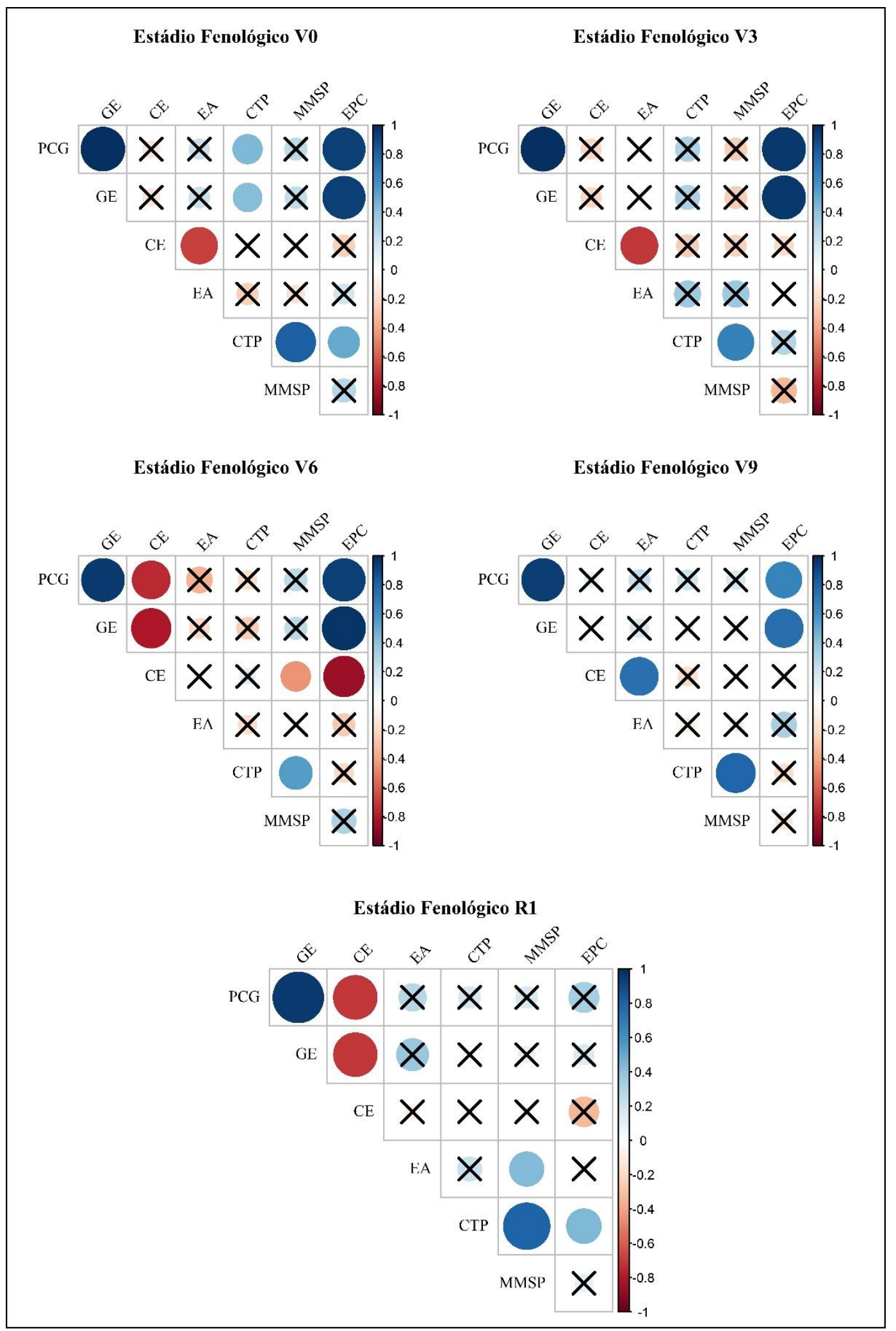

Figura 4. Resultado da análise de correlação. Símbolos marcados com X indicam correlação não significativa ( $\mathrm{p}>0,05)$. Result of correlation analysis. Symbols marked with $X$ indicate non-significant correlation ( $p>0.05$ ).

Para os estádios fenológicos V6 e R1 observou-se que houve correlação negativa significativa $(p<0,05)$ entre a primeira contagem de germinação $(P C G)$ e a germinação $(\mathrm{GE})$ 
e entre GE e condutividade elétrica (CE) (Figura 4). De modo semelhante, nos V0 e V3 foi observada correlação negativa entre CE e E

De acordo com Hampton (2002), apesar de o vigor exercer profunda influência sobre a produção de várias culturas, esses efeitos manifestam-se principalmente devido a possíveis diferenças na porcentagem de germinação e emergência das plântulas.

\section{CONCLUSÃO}

Sementes de soja com maior vigor foram obtidas com a aplicação via solo de boro na semeadura da cultura.

A qualidade fisiológica das sementes foi influenciada pela aplicação de 2,5 e 3,0 kg ha-1 de boro.

\section{REFERÊNCIAS BIBLIOGRÁFICAS}

ALMEIDA, G. M.; CANTO, M. W.; NETO, A.B.; COSTA, A.C.S. Resposta da cultura de sementes de capim-mombaça a épocas e doses de adubação de boro. Semina: Ciências Agrárias, Londrina, v. 36, n. 3, p.1545-1558, 2015.

AMBROSANO, E. J.; AMBROSANO, G. M. B.; WUTKE, E. B.; BULISANI, E. A.; MARTINS, A. L. M.; SILVEIRA, L. C. P. Efeitos da adubação nitrogenada e com micronutrientes na qualidade de sementes do feijoeiro cultivar IAC - Carioca. Bragantia, Campinas, v. 58, n. 2, p.393-399, 1999.

BANZATO, D.; KRONKA, S. A. Experimentação agrícola. Jaboticabal: Funep, 2006. 237 p.

BARBER, S. A. Soil nutrient bioavalability: a mechanistic approach. 2.ed. New York, Jonh Wiley \& Sons, 1995. 414 p.

BEVILAQUA, G. A. P.; SILVA FILHO, P. M.; POSSENTI, J. C. Aplicação foliar de cálcio e boro e componentes de rendimento e qualidade de sementes de soja. Ciência Rural, Santa Maria, v. 32, n. 1, p.31-34, 2002.

BORKET, C. M. Micronutrientes na planta. In: BÜLL, L. T.; ROSOLEM, C. A. (Ed.). Interpretação de análise química de solo e planta para fins de adubação. Botucatu: Fundação de Estudos e Pesquisas Agrícolas e Florestais, 1989, p. 309-329.

BRASIL. Padrões para produção e comercialização de sementes de soja. 2005. Disponível em: http://www.agricultura.pr.gov.br/arquivos/File/PDF/padroes_soja.pdf. Acesso em: 19 jun. 2018.

BRASIL. Ministério da Agricultura, Pecuária e Abastecimento. Secretaria de Defesa Agropecuária. Regras para análise de sementes. Brasília, DF: Mapa/ACS, 2009. 395 p.

CAKMAK, I.; RÖMHELD, B. Boron deficiencyinduced impairments of cellular functions in plant. Plant Soil, The Hague, v. 193, n. 1/2, p.71-83, 1997. 
CARVALHO, N. M.; NAKAGAWA, J. Sementes: ciência, tecnologia e produção. 4.ed. Jaboticabal: FUNEP, 2000. 588 p.

CERETTA, C. A.; PAVINATO, A.; PAVINATO, P. P. S.; MOREIRA, I. C. L.; GIROTTO, E.; TRENTIN, E. E. Micronutrientes na soja: produtividade e análise econômica. Ciência Rural, Santa Maria, v. 35, n. 3, p.576-581, 2005.

DECHEN, A. R. Micronutrientes: funções nas plantas. In: FERREIRA, M. E. (Coord.). Anais do Simpósio sobre micronutrientes na agricultura. Jaboticabal: FCAV/Unesp, 1988. p. 111-132.

FAQUIN, V. Nutrição mineral de plantas. Lavras: ESAL/FAEPE, 1994. 227 p.

FARINELli, R.; PENARIOL, F. G.; SOUZA, F. S.; PIEDADE, A. R.; LEMOS, L. B. Características agronômicas e qualidade fisiológica de sementes de cultivares de feijão adubados via foliar com cálcio e boro. Científica, Jaboticabal, v. 34, n. 1, p.59-65, 2006.

FATIMA, A. Role of boron in plasma membrane $\mathbf{H}+-$ ATPase hydrolytic and pumping activity in maize (Zea mays L.). 2013. $87 \mathrm{f}$. Thesis (Doctoral in agriculture) - Justus Liebig University Giessen, Germany, 2013.

FERREIRA, D. F. Sisvar: a computerstatisticalanalysis system. Ciência e Agrotecnologia, Lavras, v. 35, n. 6, p.1039-1042, 2011.

FRANCA-NETO, J. B.; KRZYZANOWSKI, F. C.; HENNING, A. A. Sementes de soja de alta qualidade: a base para altas produtividade. In: CONGRESO DE LA SOJA DEL MERCOSUR, 5, 2011, Rosário. Anais [...] Rosario: Asociación de la Cadena de la Soja Argentina, 2011. p. 1-4.

FURLANI, A. M. C.; TANAKA, R. T.; TARALLO, M.; VERDIAL, M. F.; MASCARENHAS, H. A. A. Exigência a boro em cultivares de soja. Revista Brasileira de Ciência do Solo, Campinas, v. 25, n. 4, p.929-937, 2001.

GAZOLLA-NETO, A.; FERNANDES, M. C.; GOMES, A. D.; GADOTTI, G. I.; VILLELA, G. A. Distribuição espacial da qualidade fisiológica de sementes de soja em campo de produção. Revista Caatinga, Mossoró, v. 28, n. 3, p.119-127, 2015.

GOMES, I. S. Aplicação de boro em diferentes estádios da cultura da soja.2016. 29 f. Dissertação (Mestrado em Produção Vegetal). Universidade Estadual de Goiás, Ipameri, 2016.

HAMPTON, J. G. What is seed quality? Seed Science and Technology, Zürich, v. 30, n. 1, p.1-10, 2002.

HANSON, E. How much boron do flowers need?. Better Crops. Atlanta, v.75, n.4, p.10-11, 1991.

HIRAKURI, M. H.; LAZZAROTTO, J. J.; Evolução e perspectivas de desempenho econômico associados com a produção de soja nos contextos mundial e brasileiro. Londrina: EMBARAPA SOJA, 2011. 47 p. (Documentos 319) 
HUANG, L. B.; BELL,R. W.; DELL, B. Estimating boron requirements for sunflower growth a B-buffered solution culture system. Communications in Soil Science and Plant Analysis, New York, v. 31, n. 11-14, p.2111-2123, 2000.

KAPPES, C.; GOLO, A. L.; CARVALHO, M. A. C. Doses e épocas de aplicação foliar de boro nas características agronômicas e qualidade de sementes de soja. Scientia Agraria, Curitiba, v. 9, n. 3, p.291-297, 2008.

KRZYZANOWSKI, F. C.; VIEIRA, R. FRANÇA NETO, J. B. Vigor de sementes: conceitos e testes. Londrina: Abrates, 1999. 210 p.

LEITE, R. F. C.; SCHUCH, L. O. B.; AMARAL, A. S.; TAVARES, L. C. Rendimento e qualidade de sementes de arroz irrigado em função da adubação com boro. Revista Brasileira de Sementes, Londrina, v. 33, n. 4, p.785-791, 2011.

LIMA, M. L.; CARDOSO, F. R.; GALANTE, A. H. A.; TEIXEIRA, G. C. S.; TEIXEIRA, I. R.; ALVES, S. M. F. Fontes e doses de boro na qualidade de sementes de feijão comum e mamona sob consórcio. Revista Caatinga, Mossoró, v. 26, n. 4, p.31-38, 2013.

LUND, S. T.; SMITH, A. G.; HACKETT, W. P. Cuttings of tabacco mutant, rac, undergo cell divisions but do not initiate adventitious roots inresponse to exogenous auxina. Physiologia Plantarum, Copenhagen, v. 97, n. 2, p.372-380, 1996.

MALAVOLTA, E. Manual de nutrição mineral de plantas. São Paulo: Agronômica Ceres, 2006. $638 \mathrm{p}$.

MARCOS FILHO, J. Fisiologia de sementes de plantas cultivadas. Piracicaba: FEALQ, 2005. $495 \mathrm{p}$.

MARSCHNER, H. Mineral nutrition of higher plants. 2. ed. New York: Academic Press. $1995.889 \mathrm{p}$.

MONDO, V. H. V.; JUNIOR, F. G. G.; PINTO, T. L. F.; MARCHI, J. L.; MOTOMIYA, A. V. A.; MOLIN, J. P.; CICERO, S. M. Spatial variability of soil fertility and its relationship with seed physiological potential in a soybean production area. Revista Brasileira de Sementes, Londrina, v. 34, n. 2, p.193-201, 2012.

NAKAGAWA, J. Testes de vigor baseados na avaliação de plântulas. In: VIEIRA, R. D.; CARVALHO, N. M. (Ed.). Testes de vigor em sementes. Jaboticabal: FUNEP, 1994. p. 4885.

NAKAGAWA, J. Testes de vigor baseados no desempenho das plântulas. In: KRZYZANOWSKI, F. C. VIEIRA, R. D.; FRANÇA NETO, J. B. (Ed.). Vigor de sementes: conceitos e testes. Londrina: ABRATES, 1999. cap. 3, p.1-24.

OBATA, H. Micro essential elements. In: MATSUO, T.; KUMAZAWA, K.; ISHII, R.; ISHIHARA, K.; HIRATA, H. (Eds). Science of the rice plant. Tokyo: Food and Agriculture Police Research Center, 1995. p. 402-417.

ONO, E. O.; RODRIGUES, J. D. Aspecto da fisiologia do enraizamento de estacas caulinares. Jaboticabal, Universidade Estadual Paulista, 1996. 83 p. 
OHSE, S.; MARODIM, V.; SANTOS, O. S.; LOPES, S. J.; MANFRON, P. A. Germinação e vigor de sementes de arroz irrigado tratadas com zinco, boro e cobre. Revista da FZVA, Uruguaiana, v. 7/8, n. 1, p.41-50, 2001.

PESKE, S. T.; BARROS, A. C .S. A.; SCHUCH, L. O. B. Produção de sementes. In: PESKE, S. T.; VIllela, F. A.; Meneghello, G. E. Sementes: Fundamentos Científicos e tecnológicos. 3.ed. Pelotas: Editora Universitária, UFPel, 2012. p. 13-104.

R CORE TEAM (2018). R: A language and environment for statistical computing. R Foundation for Statistical Computing, Vienna, Austria. Disponível em: https://www.Rproject.org/. Acesso em: 20 jan. 2019.

RIBEIRO, N. D.; SANTOS, O. S.; MENEZES, N. L. Efeito do tratamento com fontes de zinco e boro na germinação e vigor de sementes de milho. Scientia Agricola, Piracicaba, v. 51, n. 3, p.481-485, 1994.

RIBEIRO, A. C.; GUIMARÃES, P. T. G.; ALVAREZ V., V. H. (eds.). Recomendações para o uso de corretivos e fertilizantes em Minas Gerais - 5a. Aproximação. Viçosa: Universidade Federal de Viçosa, 1999. 359 p.

RITCHIE, S. W.; HANWAY, J. J.; THOMPSON, H. E.; BENSON, G. O. How a soybean plant develops. Ames: Iowa State University of Science and Technology Cooperative Extension Service, 1977. 20 p. (SPECIAL Report, 53).

ROSOLEM, C. A.; BOARETTO, A. E. A adubação foliar em soja. In: BOARETTO, A.E.; ROSOLEM, C. A. Adubação foliar. Campinas: Fundação Cargill, 1989, v. 2, p. 513-545.

SILVA, T. R. B.; SORATTO, R. P.; BÍSCARO, T.; LEMOS, L. B. Aplicação foliar de boro e cálcio no feijoeiro. Científica, Jaboticabal, v. 34, n. 1, p.46-52, 2006.

SUZANA, C. S.; BRUNETTO, A.; MARANGON, D.; TONELLO, A. A.; KULCZYNSKI, S. M. Influência da Adubação foliar sobre a qualidade fisiológica das sementes de soja armazenadas. Enciclopédia Biosfera, Centro Científico Conhecer, Goiânia, v. 8, n. 15, p.2386, 2012.

TANAKA, R. T.; MASCARENHAS, H. A. A. Soja. Nutrição, correção do solo e adubação. Campinas: Fundação Cargill, 1992. 60 p. (Série Técnica, 7)

TEIXEIRA, I. R, BORÉM, A; ARAÚJO, G. A. A; ANDRADE, M. J. B. Teores de nutrientes e qualidade fisiológica de sementes de feijão em resposta à adubação foliar com manganês e zinco. Bragantia, Campinas, v. 64, n. 1, p.83-88, 2005.

WEI, T.; SIMKO, V. $\quad$ R package "corrplot". Disponível em: https://github.com/taiyun/corrplot. Acesso em: 10 jan. 2019. 